\title{
Zi Wang* \\ The School of History and the Institute for Global History, Beijing Foreign Studies University
}

https://doi.org/10.1515/jciea-2021-2005

Published online August 19, 2021

Abstract: The School of History and the Institute for Global History of Beijing Foreign Studies University was founded in December 2017. It aims to become a significant platform in China for international scholars to conduct research on global history. The school offers course on the histories of China and regions across the world from a global perspective. In terms of research, it is the school's goal to understand history through interactions, especially the interaction between China and the world in modern terms. The school pays special attention to the fields of the history of ideas, the knowledge transfer and scholarly exchange, and the cultural and linguistic contact between the East and the West.

Keywords: The School of History and the Institute for Global History, Beijing Foreign Studies University, global perspective, multilingual, interaction

\section{Overview}

The School of History and the Institute for Global History of Beijing Foreign Studies University is a young and vibrant academic community for cutting-edge research and education in the field of global history. The Institute was founded in December 2014. On basis of that, under the direction of Professor Li Xuetao, the School was established three years later in December 2017. Over the past few years, a team of academic elites has been formed with approximately 14 academic staff, two administrative staff, eight honorary professors and fellows, 23 graduate students and 32 undergraduate students. With a multilingual background in Chinese, English, French, German, Japanese, Latin, Portuguese and Spanish, it is the School's goal to become an important platform for international scholars to conduct research on global history.

*Corresponding author: Zi Wang, Postdoctoral Researcher, School of History, Beijing Foreign Studies University, Beijing, China, E-mail: 21902@bfsu.edu.cn 


\section{Education}

The School offers courses for undergraduate and postgraduate students on the histories of China and regions across the world from a global perspective. The courses cover a wide range of areas, ranging chronologically from antiquity to the contemporary world.

\section{Research}

The School of History focuses on the research of world history since the Age of Discovery as well as the study of modern and contemporary Chinese history. With a global perspective, the School aims to understand history through interactions, especially the interaction between China and the world in modern terms. The School keeps an open-minded view towards any modes of thinking and is against any forms of centralism. In the field of world history, the School probes into the economic, social, political and cultural evolution of various countries and regions in the world, basing on the University's strength in multilingual subjects.

The School has a strong and devoted team of academic scholars specialized in various fields in global history. Structured around the specific theme of interaction, the School pays special attention to the fields of the history of ideas, the knowledge transfer and scholarly exchange, and the cultural and linguistic contact between the East and the West, providing the guiding thread for the eight research centers of the School.

Research centers attached to the School include Research Center for the History of Ideas, Research Center for Knowledge Transfer and Scholarly Exchange, Research Center for Chinese History, Research Center for Modern Cultural and Linguistic Contact between East and West, Research Center for the History of Buddhist Culture, Research Center for Translation, Research Center for Global Migration, and Research Center for Professor Wolfgang Kubin's Studies in Chinese Cultural History. It is worth mentioning that the Research Center for Professor Wolfgang Kubin's Studies in Chinese Cultural History was established basing on the School's rich sources of academic achievements of Professor Kubin who has made significant contribution to the field of sinology.

\section{Database}

Current research projects of the School give birth to the following three databases that aim to provide online platforms for academic research in the related fields: 
Database on the History of Chinese Students Abroad, Research Platform of Modern Conceptual History, and Global China Studies Online.

"Database on the History of Chinese Students Abroad" collects information on various aspects of Chinese students studying abroad since the late nineteenth century. It contains the dates of going abroad and returning to China, the country of study, the major of study, the degree obtained, and the field of employment, academic achievements, and employment after returning to the country. The database helps us to understand the pioneering role of returning students in the social development and construction of China, as well as their impacts on various academic disciplines and different aspects of social life.

"Research Platform of Modern Conceptual History" is a specialized research platform for investigating the neologisms and translated words using modern Chinese characters in East Asia. It aims to provide basic sources on the modern vocabulary exchange in the cultural circle of Chinese characters and the reconstruction of the vocabulary system of various languages in East Asia, as well as the history of modern vocabularies and concepts. The database has collected a total of 7714 homographs in modern Chinese and Japanese, with a focus on academic terms and abstract words. The database lists the origin of every one of the 7714 words from Chinese and Japanese literatures and verifies the changes of their meanings.

"Global China Studies Online" aims to build a database of multilingual literature in Chinese studies, which is able to fully demonstrate the history and current situation of Chinese studies globally. The database integrates sources on Chinese studies from both China and overseas.

\section{International Academic Events}

The School initiates close collaboration with institutions and scholars around the world, in terms of co-organizing conferences and delivering lectures. The School's honorary professors include but not limited to Professor Wolfgang Kubin and Professor Ralph Kauz from Bonn University, Professor Shen Guowei and Professor Uchida Keiichi from Kansai University, Professor Alfons Labisch from Heinrich Heine University Düsseldorf. These scholars have played significant part in building a vibrant academic environment within the School.

From 2016 to 2019, the School launched the lecture series "Global History and China" with more than 100 lectures given by leading scholars around the world. Specifically, in 2017, Professor James Z. Lee from Hong Kong University of Science 
and Technology gave an insightful talk discussing the four stages of Chinese elite education from 1865 to 2014. In 2016, Professor Akita Shigeru from Osaka University delivered a speech on the formation of cotton-centered linkages in Asia from 1890s to 1900s; Professor Alfons Labisch from Heinrich Heine University Düsseldorf shared his research on the focus, approaches and subjects on the topic of "Medicine in Global History."

Professor Li Xuetao and Professor Shen Guowei promoted the long-term cooperation between the School and the Society for Cultural Interaction in East Asia of Kansai University School. In 2017, the 9th Annual Meeting of Society for Cultural Interaction in East Asia was held in Beijing Foreign Studies University, chaired by Professor Li Xuetao. Professor Alfons Labisch delivered the keynote speech "Eurasian Transfer of Knowledge vs. Eurasian Interchange of KnowledgeThe Times Before Writing.”

\section{Publications}

The results of research projects and academic events have been published in 16 books, including monographs, seminar series and translations. Some recent publications in collaboration with publishers such as Cambridge University Press, Xinxing chubanshe (New Star Press), and Cambridge Concise Histories (in Chinese), include $A$ Concise History of the United States of America, A Concise History of Italy, A Concise History of Germany, A Concise History of Modern India, A Concise History of Russia, A Concise History of Canada, A Concise History of France, and A Concise History of Greece. With Huadong shifan daxue chubanshe (East China Normal University Press), the School published a series of translation of the monographs by Karl Jaspers, starting with The Origin and Goal of History (in Chinese). Since 2017, the School has also published, with Hakuteisha, a book series of "The Studies of Global History and East Asian Culture (in Chinese)."

About academic journals, the School has published four in Chinese, one in English and two bilingual ones in German and English. Specifically, "Global History and China (in Chinese)" is co-edited by Professor Wolfgang Kubin and Professor Li Xuetao. "Journal of Cultural Interaction in East Asia (in English)” is coedited by Professor Li Xuetao and Professor Shen Guowei from Kansai University, basing on the 9th Annual Meeting of Society for Cultural Interaction in East Asia. "minima sinica (in German and English)" and "Orientierungen (in German and English)” are co-published with Bonn University. The aforementioned journals 
contain peer-reviewed articles, book reviews and research notes, bring together some of the expertise in sinology, Chinese culture and history, and global history from China, Germany and Japan, and offer platforms for academic discussion in related fields.

\section{Website and Contact Details}

More details about the School's teaching program, past and future activities, and publications are available on the official website:

http://www.globalhistory.cn/index.htm

The School can be contacted at: E-mail: gh@bfsu.edu.cn 